\title{
Study on a Selection Strategy for Mobile Terminals of Hospital Business
}

\author{
Wu Qingbin ${ }^{1}$ \\ THE FIRST AFFILIATED HOSPITAL OF JINAN UNIVERSITY \\ GUANGDONG 510630 \\ Meng Yu \\ THE FIRST AFFILIATED HOSPITAL OF JINAN \\ UNIVERSITY GUANGDONG 510630
}

\begin{abstract}
- as a bridge between mobile application and users, the mobile terminal is a key part of the whole mobile health. Therefore, how to select appropriate terminals for different application scenarios and user requirements is the first issue to be solved currently in the process of building mobile health system in hospitals. By establishing the index system of terminals and application scenarios, this study puts forward an idea to objectively select terminals, which is of guiding significance for selecting terminals under particular scenarios.
\end{abstract}

Keywords: Selection Strategy, Mobile Terminals, Hospital Business, Management.

\section{INTRODUCTION}

Mobile health (hereinafter referred to as m-health) refers to an emerging health care mode integrating mobile computing, medical sensing and communication technology ${ }^{[1]}$. Compared with the traditional application based on PC, m-health can provide more efficient medical services. With the continuous improvement of speed, stability and safety in mobile network, the application range of $m$-health is wider and wider. M-health technology offers great convenience for not only ward rounds of doctors and bedside care of nurses, but also register of patient and query of report results.

With the increasing application range of m-health, different application scenarios are implemented by different terminals. For instance, doctors need a cart or tablet to achieve mobile ward rounds; nurses need a PDA (Personal Digital Assistant) or smartphone to carry out bedside nursing tasks; managers need a tablet ot smartphone for evaluation and administrative work; and patients need their own communication facilities to communicate with doctors ${ }^{[2]}$. Therefore, the matching degree of terminals with network and APP determines the success degree of the whole mobile application.

Through applying the mobile application system in nearly 50 ward areas on the $27^{\text {th }}$ floor and two-year continuous improvement, mobile doctor station and mobile nurse station were applied in $80 \%$ ward areas. While applying the two systems, medical workers need to operate various terminals and different users have varying terminal preference under different scenarios. Hence, it is of practical guiding significance to conduct questionnaire survey on the mobile terminal selection of medical workers who applied m-health system in the hospital.

\section{Problems}

In the project startup period of m-health system, it is always a disturbing problem for hospital information management department to select appropriate terminals for different user roles under different business scenarios. Even there are different selection schemes for different ward areas, because each hospital has its own unique objective conditions and management 
culture and the clinical departments of hospitals also show different objective conditions. Thus, it is difficult to achieve the expected effects by merely referring to the terminal selection schemes of other hospitals. A method is needed to enable various users in the system to find their suitable mobile terminals accordingly.

\section{Solution ideas}

As for the application range of mobile terminals or m-health, it can be classified into public network and internal network from the aspect of network nature; or patient application, healthcare application and management application from the aspect of targeted users $^{[3]}$. Hence, the emphasis of different healthcare scenarios on the smart terminals varies. For example, when doctors go the rounds of the wards, they need to quickly check the information of medical orders, bed records and inspection reports of each certain patient. Therefore, the terminal screen for doctors should be large enough and they usually select carts or tablets as the smart terminals. The following part mainly describes an idea of objectively selecting m-health terminal types so as to build a matching model of $\mathrm{m}$-health terminal and certain application scenarios for hospitals.

Mobile terminal matching degree refers to the degree to which a mobile terminal applies to a specific application scenario. It plays a guiding role in selecting mobile terminals. There are two steps to construct the mobile terminal matching model: the first is to establish a mobile terminal index system and the second is to calculate the index weight.

Mobile terminal matching degree refers to the degree to which a mobile terminal applies to a specific application scenario. It plays a guiding role in selecting mobile terminals. There are two steps to construct the mobile terminal matching model: the first is to establish a mobile terminal index system and the second is to calculate the index weight.
1) Mobile terminal index system

Based on questionnaire survey and discussion with experts, we have generalized the factors influencing matching degree calculation as shown in table 1.

Table 1 Matching model index system

\begin{tabular}{|l|}
\hline Portability (F1) \\
\hline Convenience of operation (F2) \\
\hline Sterilizability (F3) \\
\hline Anti-theft performance (F4) \\
\hline vulnerability (F5) \\
\hline PC application portability (F6) \\
\hline
\end{tabular}

The calculation formula of matching degree is:

Match $=\sum_{i=1}^{6} \mathrm{w}_{i} * \mathrm{M}\left(\mathrm{F}_{i}\right)$

In this formula, Match represents the total matching degree, $\mathrm{M}\left(\mathrm{F}_{i}\right)$ represents the matching degree of index $i$ and $\mathrm{w}_{i}$ represents the weight of index $i$. The calculation formula of a single index matching degree is:

$$
M\left(\mathrm{~F}_{i}\right)=\left\{\begin{array}{c}
1 \quad m f i>=s f i \\
m f i / s f i \quad m f i<s f i
\end{array}\right.
$$

In this formula, $m f i$ and $s f i$ respectively represent the score of mobile terminal's factor $i$ influencing the matching degree and evaluation score of application scenario's requirement for factor $i$.

2) Calculation of the index weight

Subjective weighting and objective weighting are two basic methods to determine index weight. Due to the lack of historical data, index weight of the match model can only be determined by subjective weighting method. Subjective weighting method determines the relative significance among different indexes on the basis of scoring by actual users or experts. In this study, we have determined the index weight through questionnaire survey of which the objects are actual mobile terminal users (doctors or nurses). The 
execution steps were performed as follows:

(1) Collect data from questionnaire survey to get the total score of each factor. As this survey mainly aimed to obtain actual users' perception of the degree to which each factor contributes to the comprehensive objective during their daily usage of mobile terminals and did not investigate the relative significance between any two indexes, this step determines the significance of indexes according to each factor's total contribution to the comprehensive objective.

(2) Normalize each factor's total score to get their weight. Because each index's significance obtained from step (1) is a relative value, each index's total contribution needs to be normalized. This can be calculated by formula (c).

$r_{i}=\frac{c_{i}}{\sum_{j=1 \ldots n} c_{j}} \quad i=1 \ldots n$
In this formula, $\mathrm{c}_{\mathrm{i}}$ represents the total contribution of index $i$ and $r_{i}$ represents the final weight of index i.

(3) Application of model

In order to find out m-health's requirement for mobile terminals, we have conducted a questionnaire investigation on doctors and nurses in our hospital (questionnaire see annex 1). 100 questionnaires were distributed and 98 were received. Not counting the 5 invalid questionnaires included in the received questionnaires, we have finally received 93 valid questionnaires. The data were collected to obtain each factor's score and each index's weight was calculated by index weight calculation method in (2). The results are shown in table 2 .

Table 2 Results of index weight

\begin{tabular}{|l|l|}
\hline Factors & weight \\
\hline Portability & 0.219888 \\
\hline Convenience of operation & 0.22549 \\
\hline Sterilizability & 0.10084 \\
\hline Anti-theft performance & 0.166667 \\
\hline Vulnerability & 0.102241 \\
\hline PC application portability & 0.184874 \\
\hline
\end{tabular}

In addition, this study has calculated the requirement for each index of mobile terminals in different m-health application scenarios. The results are shown in table 3. 
Table 3 Requirement for each index of mobile terminals (5 mark scoring)

\begin{tabular}{|l|l|l|l|l|l|l|}
\hline $\begin{array}{l}\text { Average score of } \\
\text { application scenarios }\end{array}$ & Portability & $\begin{array}{l}\text { Convenience } \\
\text { of operation }\end{array}$ & Sterilizability & $\begin{array}{l}\text { Anti-theft } \\
\text { performance }\end{array}$ & Vulnerability & $\begin{array}{l}\text { PC application } \\
\text { portability }\end{array}$ \\
\hline $\begin{array}{l}\text { Ward rounds by } \\
\text { doctors perform }\end{array}$ & 4.47 & 4.09 & 3.09 & 2.74 & 3.03 & 3.24 \\
\hline $\begin{array}{l}\text { Nurses near } \\
\text { medical orders ned } \\
\text { the bed }\end{array}$ & 3.6 & 3.5 & 3.13 & 2.9 & 2.85 & 2.57 \\
\hline $\begin{array}{l}\text { Nurses educate } \\
\text { patients near the bed }\end{array}$ & 3.8 & 3.45 & 3.28 & 3.15 & 2.85 & 2.48 \\
\hline $\begin{array}{l}\text { Nurses record } \\
\text { patients vital sign } \\
\text { near the bed }\end{array}$ & 3.87 & 3.67 & 3.317 & 3.18 & 3.02 & 2.57 \\
\hline
\end{tabular}

In order to select proper terminals for different application scenarios, different terminals were scored in terms of each index. The results are shown in table 4 .

Table 4 Score of terminal performance (5 mark scoring)

\begin{tabular}{|c|c|c|c|c|c|c|}
\hline Terminals & Portability & $\begin{array}{l}\text { Convenience } \\
\text { of operation }\end{array}$ & Sterilizability & $\begin{array}{l}\text { Anti-theft } \\
\text { performance }\end{array}$ & Vulnerability & $\begin{array}{l}\text { PC application } \\
\text { portability }\end{array}$ \\
\hline Integrated carts & 2 & 5 & 5 & 5 & 4 & 5 \\
\hline Notebook carts & 2 & 5 & 3 & 4 & 3 & 5 \\
\hline IPAD & 4 & 3 & 2 & 2 & 1 & 2 \\
\hline $\begin{array}{l}\text { PDA } \\
\text { keyboards) }\end{array}$ & 4 & 1 & 5 & 2 & 5 & 2 \\
\hline $\begin{array}{l}\text { Industrial-grade PAD } \\
\text { with a size of } 5.5 \text { inch }\end{array}$ & 5 & 3 & 5 & 2 & 4 & 2 \\
\hline Smart phone & 5 & 2 & 2 & 2 & 1 & 2 \\
\hline
\end{tabular}


Table 5 Match degree between application scenarios and mobile terminals

\begin{tabular}{|c|c|c|c|c|c|c|c|}
\hline & $\begin{array}{l}\text { Ward } \\
\text { rounds } \\
\text { by } \\
\text { doctors }\end{array}$ & & $\begin{array}{l}\text { Nurses } \\
\text { perform } \\
\text { medical } \\
\text { orders } \\
\text { near the } \\
\text { bed }\end{array}$ & & $\begin{array}{l}\text { Nurses } \\
\text { educate } \\
\text { patients } \\
\text { near } \\
\text { the bed }\end{array}$ & & $\begin{array}{l}\text { Nurses record } \\
\text { patients' vital } \\
\text { sign near the } \\
\text { bed }\end{array}$ \\
\hline Integrated carts & 0.829 & $\begin{array}{l}\text { Industrial-grade } \\
\text { PAD with a } \\
\text { size of } 5.5 \text { inch }\end{array}$ & 0.875 & $\begin{array}{l}\text { Industrial-grade } \\
\text { PAD with a } \\
\text { size of } 5.5 \text { inch }\end{array}$ & 0.874 & $\begin{array}{l}\text { Industrial-grade } \\
\text { PAD with a } \\
\text { size of } 5.5 \text { inch }\end{array}$ & 0.856 \\
\hline Notebook carts & 0.825 & Integrated carts & 0.841 & Integrated carts & 0.838 & Integrated carts & 0.837 \\
\hline $\begin{array}{l}\text { Industrial-grade } \\
\text { PAD with a } \\
\text { size of } 5.5 \text { inch }\end{array}$ & 0.824 & Notebook carts & 0.837 & Notebook carts & 0.829 & Notebook carts & 0.827 \\
\hline IPAD & 0.697 & IPAD & 0.772 & PAD & 0.768 & IPAD & 0.748 \\
\hline $\begin{array}{l}\text { PDA (with } \\
\text { keyboards) }\end{array}$ & 0.691 & $\begin{array}{l}\text { PDA (with } \\
\text { keyboards) }\end{array}$ & 0.746 & $\begin{array}{l}\text { PDA (with } \\
\text { keyboards) }\end{array}$ & 0.743 & $\begin{array}{l}\text { PDA (with } \\
\text { keyboards) }\end{array}$ & 0.733 \\
\hline Smart phone & 0.665 & Smart phone & 0.708 & Smart phone & 0.703 & Smart phone & 0.686 \\
\hline
\end{tabular}

\section{Conclusion}

This study has proposed an objective and quantified method to guide the selection of terminals in m-health. First, we have established a mobile terminal index system and obtained the index weight by questionnaire survey. Table 2 indicates that users attach relatively more importance to terminal's portability and convenience of operation which can basically satisfy actual users' practical demand. Second, we have obtained the score of the four different application scenarios' requirement for each index of mobile terminals as shown in table 3 and the score of six terminals' performance as shown in table 4. Last, matching degree was calculated by formula (a).

From table 5 we find that in "ward rounds by doctors" scenario, the matching degree of integrated carts, notebook carts and industrial-grade PAD with a size of 5.5 inch are as high as over 0.8 , while that of IPAD, PAD (with keyboards) and smart phone is relatively lower. Likewise, the matching degree of the six terminals in "nurses perform medical orders", "nurses educate patients near the bed" and "nurses record patients' vital sign" scenarios is similar to that in "ward rounds by doctors" scenario. Among all the terminals, the match degree of industrial-grade PAD with a size of 5.5 inch is the highest and it almost tops the listed clinical scenarios in our hospital. On the contrary, the match degree of the frequently used smart phone and IPAD in daily life is quite low in these scenarios. In particular, smart phone, a commonly used device brought by employees who are advocated to bring it to work by many companies, has the lowest matching degree. Therefore, it can be concluded that BYOD (Bring Your Own Device) is not welcomed in our hospital wards mainly for the risk of hospital infection and loss of personal property.

In this paper, we have only provided an idea of selecting terminals. Many details of the method to realize this idea requires further study which includes integrity of the index system, scientific research and methods to obtain index weight. This study determined index weight mainly by indexes' contribution to the comprehensive objective and did not consider the relative significance between any two indexes. 
Questionnaire survey is suggested to be conducted to research this issue. Then index weight can be obtained by the analytic hierarchy process and calculation formula can be optimized and so on.

\section{Acknowledgements}

Funding: This study was supported by grants from the Science and Technology Planning Project of Guangdong Province,China (2013B040404005).and Important Guangdong Province Science \& Technology Specific Projects (2015B010106003)

\section{Reference}

[1] Istepanian R, Jovanov E, Zhang YT. Introduction to the special section on m-health: Beyond seamless mobility and global, wireless health-care connectivity [J]. IEEE Trans Inf Technol Biomed, 2004, 8(4): 405-414.

[2] Liu H. Application and development of mobile health. Chinese Digital Medical [J], 2013, 8(5): 113.

[3] Wei JF \& Ye JT. An exploration and practice of hospital mobile application based on smart phone, Chinese Digital Medical [J], 2013, 8 (7): 25-28. 